\title{
Investigation of the piroplasm diversity circulating in wildlife and cattle of the greater Kafue ecosystem, Zambia
}

\author{
David Squarre ${ }^{1,2,3 \dagger}$, Yukiko Nakamura ${ }^{1 \dagger}$, Kyoko Hayashida ${ }^{1,6}$, Naoko Kawai ${ }^{1}$, Herman Chambaro ${ }^{1,4}$, \\ Boniface Namangala ${ }^{5}$, Chihiro Sugimoto ${ }^{1}$ and Junya Yamagishi ${ }^{1,6^{*}}$
}

\begin{abstract}
Background: Piroplasms are vector-borne intracellular hemoprotozoan parasites that infect wildlife and livestock. Wildlife species are reservoir hosts to a diversity of piroplasms and play an important role in the circulation, maintenance and evolution of these parasites. The potential for likely spillover of both pathogenic and non-pathogenic piroplasm parasites from wild life to livestock is underlined when a common ecological niche is shared in the presence of a competent vector.

Method: To investigate piroplasm diversity in wildlife and the cattle population of the greater Kafue ecosystem, we utilized PCR to amplify the $18 \mathrm{~S}$ rRNA V4 hyper-variable region and meta-barcoding strategy using the Illumina MiSeq sequencing platform and amplicon sequence variant (ASV)-based bioinformatics pipeline to generate high-resolution data that discriminate sequences down to a single nucleotide difference.

Results: A parasite community of 45 ASVs corresponding to 23 species consisting of 4 genera of Babesia, Theileria, Hepatozoon and Colpodella, were identified in wildlife and the cattle population from the study area. Theileria species were detected in buffalo, impala, hartebeest, sable antelope, sitatunga, wild dog and cattle. In contrast, Babesia species were only observed in cattle and wild dog. Our results demonstrate possible spillover of these hemoprotozoan parasites from wildlife, especially buffalo, to the cattle population in the wild life-livestock interface.

Conclusion: We demonstrated that the deep amplicon sequencing of the 18S rRNA V4 hyper-variable region for wild life was informative. Our results illustrated the diversity of piroplasma and the specificity of their hosts. They led us to speculate a possible ecological cycle including transmission from wildlife to domestic animals in the greater Kafue ecosystem. Thus, this approach may contribute to the establishment of appropriate disease control strategies in wildlife-livestock interface areas.
\end{abstract}

Keywords: Piroplasma, Meta-barcoding, Kafue ecosystem, Zambia

*Correspondence: junya@czc.hokudai.ac.jp

${ }^{\dagger}$ David Squarre and Yukiko Nakamura contributed equally to this work

${ }^{1}$ Research Center for Zoonosis Control, Hokkaido University, Sapporo, Japan

Full list of author information is available at the end of the article

\section{Background}

Piroplasmida is an order of intracellular heamoprotozoan parasites that belong to the phylum Apicomplexa. The species of genera Theileria and Babesia cause clinical disease in vertebrate hosts including domestic and wild animals $[1,2]$. The parasites are transmitted by vectors of ixodid ticks and have a considerable socio-economic impact on livestock production in sub-Saharan Africa, threatening livelihoods and food security [3]. The

c) The Author(s) 2020. This article is licensed under a Creative Commons Attribution 4.0 International License, which permits use, sharing, adaptation, distribution and reproduction in any medium or format, as long as you give appropriate credit to the original author(s) and the source, provide a link to the Creative Commons licence, and indicate if changes were made. The images or other third party material in this article are included in the article's Creative Commons licence, unless indicated otherwise in a credit line to the material. If material is not included in the article's Creative Commons licence and your intended use is not permitted by statutory regulation or exceeds the permitted use, you will need to obtain permission directly from the copyright holder. To view a copy of this licence, visit http://creativeco mmons.org/licenses/by/4.0/. The Creative Commons Public Domain Dedication waiver (http://creativecommons.org/publicdomain/ zero/1.0/) applies to the data made available in this article, unless otherwise stated in a credit line to the data. 
Theileria and Babesia genera consist of a wide diversity of species and genotypes $[4,5]$.

Wildlife plays an important role in the circulation, maintenance and evolution of these parasites. African buffalos (Syncerus caffer), for example, are reservoirs of buffalo-derived Theileria parva, which causes theileriosis or corridor disease in cattle $[6,7]$. This disease is transmitted from buffalo to cattle and not between cattle, because cattle acutely die before piroplasms emerge or infect new ticks $[8,9]$. Conversely, in East Coast fever (ECF) caused by $T$. parva circulating among the cattle population, some infected cattle survive because of the immune response and occasional chemotherapy and then become asymptomatic carriers, leading to the continuous spread of the parasite among cattle [10].

Although Theileria is by far the most important piroplasma having a considerable effect on livestock production, Babesia also cause a wide range of infectious diseases in domestic animals. Redwater in cattle, canine babesiosis and equine piroplasmosis are caused by Babesia bigemina/B. bovis, B. canis and B. caballi/B. equi, respectively. Several wildlife species are natural hosts of a wide diversity of piroplasma that are either pathogenic or non-pathogenic to domestic animals.

The greater Kafue ecosystem, measuring $68,000 \mathrm{~km}^{2}$ in size, is a large conservation area in central Zambia. It is composed of the Kafue National Park $\left(22,400 \mathrm{~km}^{2}\right)$ and nine adjacent game management area (GMAs) that act as a buffer to the national park. The national park is host to numerous wildlife species and particularly is devoid of human settlements and livestock. The GMAs that immediately surround the park are notably characteristic of wildlife cohabiting with communities and their livestock, thus forming a wildlife-livestock interface area [11, 12]. The potential for likely spillover of arthropod-borne pathogens such as piroplasmas from wildlife to livestock occurs when a common ecological niche is shared in the presence of a competent vector [13]. In addition to the interface in conservation areas, the growing game ranching industry in Zambia has integrated wildlife and livestock farming, creating widespread patches of ex-situ wildlife-livestock interface areas across the country. The primary source of wildlife for stocking game ranches is conservation areas such as the greater Kafue ecosystem. This is likely to spread parasites and create a vortex of piroplasm parasites across the country.

Highlighting comprehensive piroplasm parasite community composition including cryptic species/genotype diversity of circulating parasites in the wildlife, livestock and vector population is essential to understand disease ecology and to prepare optimized countermeasures. A reservoir of important pathogens and their transmission path will be illustrated by this approach. Interaction between pathogens under mixed infection, which may cause discriminated manifestation, is another interest. Understanding the parasite community also has implications for the choice of assays to adopt in control options such as calf immunization and in epidemiology studies of piroplasm infections [14-18]. It provides basic information for the selection of live or recombinant vaccines to be used in a specific area as well [19].

To investigate the parasite diversity, deep amplicon sequencing of the $18 \mathrm{~S}$ rRNA V4 hyper-variable region by next-generation sequencing (NGS) technology has been developed [14, 17, 20, 21]. The scheme has been adopted for cattle [20], African buffalo [14, 17], Asian buffalo, cattle and sheep [21]. We also adopted the scheme and expanded the target to whole wildlife in this study to investigate and illustrate the diversity of the piroplasm community in wildlife and cattle in a discrete geographical region of the greater Kafue ecosystem of Zambia.

\section{Methods \\ Sample collection and DNA extraction}

The greater Kafue ecosystem (Fig. 1) is a conservation area located in central Zambia $\left(14^{\circ} 03^{\prime \prime} \mathrm{S} / 16^{\circ} 43^{\prime \prime} \mathrm{S}\right.$ and $25^{\circ} 13^{\prime \prime} \mathrm{E} / 26^{\circ} 46^{\prime \prime} \mathrm{E}$ ) measuring about $67,806 \mathrm{~km}^{2}$ in size. Whole-blood samples were collected from wild animals captured during a restocking program conducted between May and August of 2017 and 2018. Approximately $5 \mathrm{~mL}$ of blood was collected through venipuncture into EDTA vacutainers and immediately placed on ice. The samples were collected from 253 wild animals consisting of 12 wildlife species (Table 1) during chemical immobilization and physical restraint as previously described [22, 23]. An additional 232 blood samples were collected from cattle in the interface between the GMA and open area in Zambia's Itezhi-Tezhi district between April and May 2019 (Table 1).

From each blood sample collected, genomic DNA was extracted using the DNA Isolation Kit for Mammalian Blood (Roche Applied Science, Indianapolis, IN, USA) for wild animal samples and QuickGene DNA Whole-Blood Kit $\mathrm{S}$ (Kurabo, Osaka, Japan) for cattle samples as per the manufacturer's protocol. A final volume of $200 \mu \mathrm{L}$ DNA was eluted in tubes and stored at $-80^{\circ} \mathrm{C}$ until analysis.

\section{RLB-PCR amplification and library preparation}

Amplification of the V4 hypervariable region of the $18 \mathrm{~S}$ rRNA gene was obtained by piroplasma-specific RLB-PCR using primers RLB-F and RLB-R (Table 2) [24]. The $10 \mu \mathrm{L}$ reaction mix contained 5.0 $\mu \mathrm{L}$ Ampdirect plus buffer (Shimadzu, Kyoto, Japan), $3.95 \mu \mathrm{L}$ PCRgrade water, $0.05 \mu \mathrm{L}$ Bio Taq HS (Bioline, London, UK), $0.5 \mu \mathrm{L}$ DNA template and $0.25 \mu \mathrm{L}$ each of the RLB primers. The thermocycler conditions were $94{ }^{\circ} \mathrm{C}$ for $10 \mathrm{~min}$ 


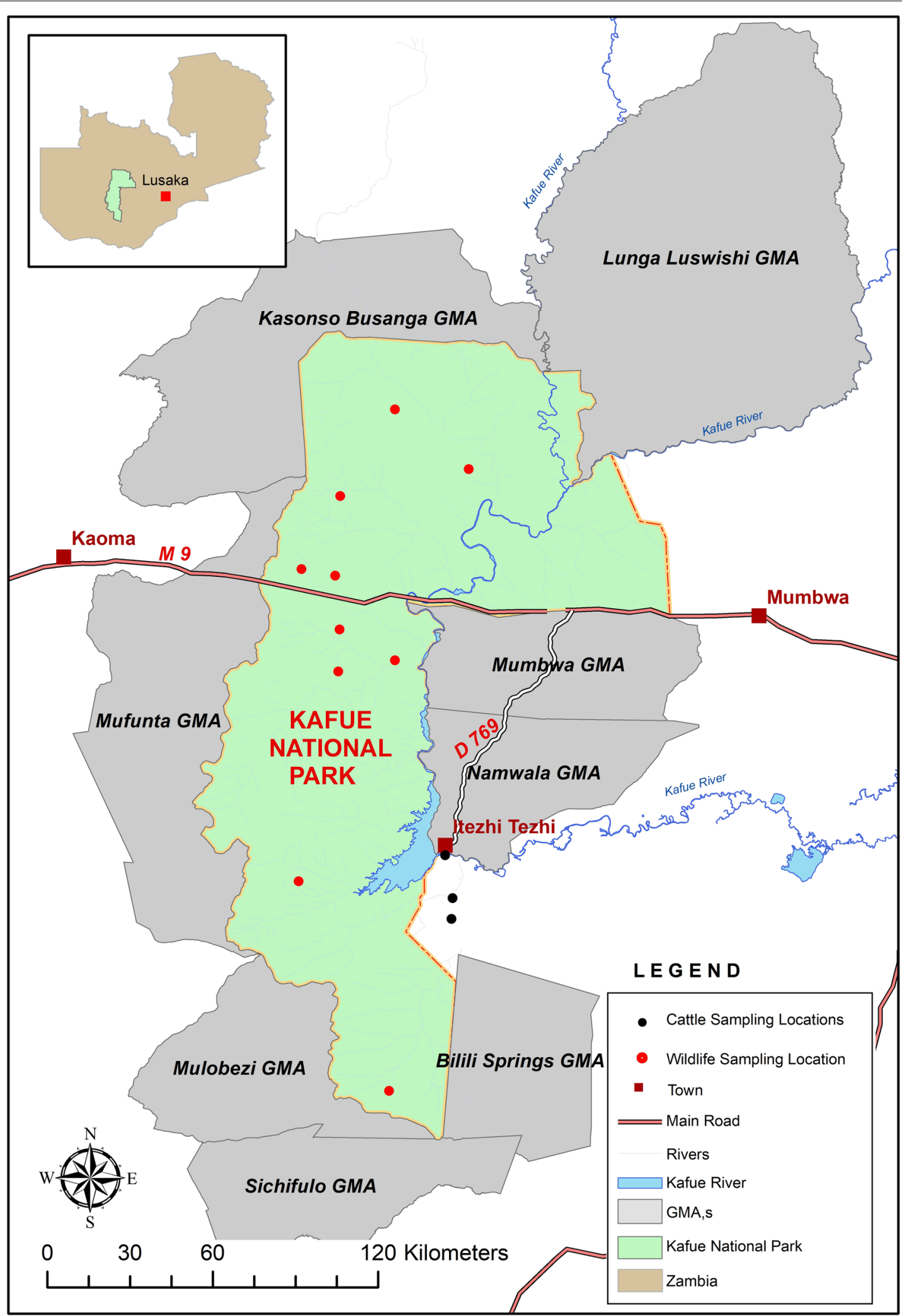

Fig. 1 Map of the Kafue ecosystem consisting of the Kafue National Park and the game management areas (GMAs) showing sampling sites of wildlife and cattle 
Table 1 Detection of heamoparasites in wildlife species and cattle from the Kafue ecosystem using RLB-PCR

\begin{tabular}{lllll}
\hline & Species sampled & Number & RLB-PCR positive & Positive rate (\%) \\
\hline 1 & Impala (Aepyceros melampus) & 106 & 65 & 61.3 \\
2 & Hartebeest (Alcelaphus buselaphus) & 47 & 19 & 40.0 \\
3 & Sable antelope (Hippotragus niger) & 8 & 8 & 100 \\
4 & Lion (Panthera leo) & 4 & 1 & 25.0 \\
5 & Wild dog (Lycaon pictus) & 2 & 2 & 100 \\
6 & Sitatunga (Tragelaphus spekii) & 4 & 3 & 74.0 \\
7 & Buffalo (Syncerus caffer) & 53 & 33 & 62.3 \\
8 & Lechwe (Kobus lecheleche) & 9 & 0 & 0.0 \\
9 & Cheetah (Acinonyx jubatus) & \multicolumn{1}{c}{} & 0.0 \\
10 & Vevert monkey (Chlorocebus pygerythrus) & 1 & 0 & 0.0 \\
11 & Baboon (Papio ursinus) & 1 & 0 & 0.0 \\
12 & Warthog (Phacochoerus africanus) & 17 & 0 & 0.0 \\
13 & Cattle (Bos taurus) & 232 & 0 & 63.4 \\
& Total & 483 & 147 & 57.6 \\
\hline
\end{tabular}

Table 2 Primers used for piroplasm parasite detection

\begin{tabular}{|c|c|c|c|}
\hline Primer's target region & Primer name & Primer sequence $\left(5^{\prime}-3^{\prime}\right)$ & References \\
\hline \multirow[t]{2}{*}{ 18S rRNA V4 hyper-variable region } & Reverse Line Blot-F (RLB-F) & GAGGTAGTGACAAGAAATAACAATA & [24] \\
\hline & Reverse Line Blot-R (RLB-R) & TCTTCGATCCCCTAACTTTC & \\
\hline \multirow[t]{2}{*}{ Illumine tail-tagged RLB primer } & Illumina RLB-F & ACACTCTTTCCCTACACGACGCTCTTCCGATCT[RLB-F] & \\
\hline & Illumina RLB-R & GTGACTGGAGTTCAGACGTGTGCTCTTCCGATCT[RLB-R] & \\
\hline \multirow[t]{2}{*}{ Illumina-index primer } & Illumina-i5 primers & $\begin{array}{l}\text { AATGATACGGCGACCACCGAGATCTACAC[index*] ACACTC } \\
\text { TTTCCCTACACGACGCTCTTCCGATCT }\end{array}$ & \\
\hline & Illumina-i7 primers & $\begin{array}{l}\text { CAAGCAGAAGACGGCATACGAGAT[index*] GTGACTGGAGTT } \\
\text { CAGACGTGTGCTCTTCCGATCT }\end{array}$ & \\
\hline
\end{tabular}

* Index: 8-bp nucleotide to provide a unique index to each sample

denaturation and 40 cycles of $94{ }^{\circ} \mathrm{C}$ for $1 \mathrm{~min}$, annealing at $50{ }^{\circ} \mathrm{C}$ for $1 \mathrm{~min}$, extension at $72{ }^{\circ} \mathrm{C}$ for $1.5 \mathrm{~min}$ and final extension at $72{ }^{\circ} \mathrm{C}$ for $10 \mathrm{~min}$.

The second PCR adding Illumina tail was conducted using 100 times diluted first PCR amplicons as template. The reaction volume of $10 \mu \mathrm{L}$ comprised the same volumes of reagents as the first RLB-PCR but instead replaced the primer with $10 \mu \mathrm{M}$ Illumina tail-tagged RLB primers (Table 2). The thermocycler conditions were the same as for the first PCR except amplification was set at 12 cycles.

The Illumina tail-tagged amplicons from the second PCR were then diluted 50 times, and $1 \mu \mathrm{L}$ was added to a $20 \mu \mathrm{L}$ reaction mixture for index PCR. The other reagents included $4 \mu \mathrm{L}$ of $5 \times$ buffer, $1.4 \mu \mathrm{L} \mathrm{MgCl}_{2}(25 \mathrm{mM}), 0.5 \mu \mathrm{L}$ $10 \mathrm{mM}$ dNTP mix, $1 \mu \mathrm{L}$ mixed Illumina-index primer (Table 2), $11.975 \mu \mathrm{L}$ nuclease-free water and $0.125 \mu \mathrm{L}$ KAPATaq Extra. The indexing PCR was run with thermocycler conditions of $95{ }^{\circ} \mathrm{C}$ initial denaturation for $5 \mathrm{~min}$ followed by 15 cycles of $92{ }^{\circ} \mathrm{C}$ for $30 \mathrm{~s}, 45^{\circ} \mathrm{C}$ for $30 \mathrm{~s}$ and
$72{ }^{\circ} \mathrm{C}$ for $30 \mathrm{~s}$ and a final extension at $72{ }^{\circ} \mathrm{C}$ for $15 \mathrm{~min}$. The obtained amplicons, which have a unique 8-bp index on both sides for each sample, were quantified by agarose gel electrophoresis. Then, an equal amount of each sample was pooled into one library and gel-purified using Wizard SV Gel and the PCR Clean-Up System (Promega, Madison, WI, USA).

\section{Amplicon sequencing and bioinformatic analysis}

The RLB-PCR amplicon library was sequenced with the MiSeq $[17,21]$ using a 300-bp paired-end sequencing protocol and the MiSeq Sequencing Reagent Kit v3 (Illumina, Hayward, CA, USA) with $25 \%$ PhiX DNA spikein control according to the manufacturer's instructions. Quality control and filtering were conducted with Trimmomatic [25] using the following parameters: TRAILING:20, SLIDINGWINDOW:4:15 and MINLEN:36. Concatenation between forward and reverse reads and primer trimming was conducted with AMPtk [26], allowing a minimum merged length of $400 \mathrm{bp}$. Primer 
sequences to be trimmed were GAGGTAGTGACAAGA AATAACAATA and TCTTCGATCCCCTAACTTTC for forward and reverse reads, respectively.

A set of amplicon sequence variants (ASVs) was generated by DADA2 and LULU in the AMPtk package using the default parameters. The obtained sequences were annotated based on sequence homology with the Basic Local Alignment Tool (BLAST) and non-redundant nucleotide database by NCBI using -max_target_seqs 1 , -perc_identity 70, -qcov_hsp_perc 70 and -evalue 1e-20 as a set of parameters [27]. Operational taxonomic units (OTUs) were further generated by clustering the ASVs using usearch [28] with $99 \%$ identity as clustering threshold. Observed ASVs in each sample were filtered out if the number of the assigned reads was $<1 \%$ of the total number of assigned reads.

\section{Phylogenetic analyses}

The phylogenetic relationships among ASVs were analyzed using the neighbor-joining method [29] implemented in MEGA X [30]. The evolutionary distances were computed using the maximum composite likelihood method [31] and default parameters with 10,000 bootstraps. Visualization and annotation were conducted using iTOL v5.5 [32]. Each clade was annotated based on sequence identity obtained by the BLAST analysis.

\section{Results}

\section{Detection of the piroplasm parasite by PCR and taxonomical annotation}

Of 253 sampled wild animals, 61.3\% (65/106) of impalas, $40 \%$ (19/47) of hartebeests, $62.3 \%$ (33/53) of buffalos, $74 \%$ $(3 / 4)$ of sitatungas, $25 \%(1 / 4)$ of lions and all the sable antelope $(8 / 8)$ and wild dogs $(2 / 2)$ were positive for piroplasmosis by RLB-PCR. In case of cattle, 63.4\% (147/232) were RLB-PCR positive. Of the 12 wildlife species sampled and screened, 7 species were infected by piroplasm parasites (Table 1, Additional file 1: Table S1). All the positive amplicons were subjected to sequence analysis to identify their taxonomic classification. In total, $2.80 \mathrm{M}$ raw reads were obtained from 278 PCR positive samples and then merged into $2.46 \mathrm{M}$ contigs (Additional file 1: Table S1).

A total of 45 ASVs of the V4 hyper-variable region of the 18S rRNA gene were obtained from both wildlife species and cattle sampled from the greater Kafue ecosystem (Table 3). The taxonomic assignment of ASV using BLASTn resulted in the identification of four genera, Theileria, Babesia, Hepatozoon and Colpodella, which consisted of 11, 3, 2 and 1 known species and 36, 6, 2 and 1 ASVs, respectively (Additional file 1: Table S1).

In the phylogenetic analysis, we observed both Theileria and Babesia clade (Fig. 2). The Theileria clade consisted of a subclade for T. velifera, T. mutans, T. parva and T. taurotragi.

The $T$. velifera subclade consisted of seven ASVs, and sequence identity to T. velifera was $98.7 \%$ to $100 \%$ (Table 3), suggesting all of these ASVs belong to T. velifera. The subclade was further divided into two groups based on sequence identity. One was ASV6, 29 and 55, which were detected only in buffalo; ASV7, 64 and 92 were detected only in cattle while ASV1 was detected in cattle and impala (Fig. 2, Additional file 1: Table S1).

A similar correlation among sequence identity and hosts was observed in the T. mutans clade. ASV26, 42 and 60 were buffalo specific, and ASV3, 5, 16 were detected in both buffalo and cattle. All of them had more than $99.5 \%$ identity to the reference sequences of $T$. mutans (Fig. 2, Additional file 1: Table S1, Table 3).

Interestingly, most of the observed ASVs in the $T$. parva clade were detected only in buffalo except ASV15 (T. parva) and ASV11 (Theileria sp. buffalo), which were detected in both buffalo and cattle (Na032 and Na142, respectively) (Additional file 1: Table S1). ASV25 showed $100 \%$ identity to Theileria sp. bougasvlei but was adjacent to the T. parva clade (Table 3, Fig. 2).

T. taurotragi was detected in four cattle. ASV46 and 62 had $>99.8 \%$ identity to a T. taurotragi reference sequence but ASV35 had $97.8 \%$ identity, implying this can be categorized in a different genotype (Table 3).

There were two additional clades in Theileria (Fig. 2). One consisted of ASV8, 9, 14, 23, 49 and 85. It was almost exclusively detected in hartebeest even though ASV8 and 23 were also detected in a wild $\operatorname{dog}(\mathrm{Da} 082)$. They showed high identity to unspecified Theileria spp. The other consisted of ASV2, 47 and 106, which were detected in impala. ASV4 was detected in both hartebeest and sable antelope but also found in a buffalo (Da109). ASV12 and 13 were detected in sitatunga.

The Babesia clade consisted of a subclade for $B$. bigemina and B. occultans. ASVs in the B. bigemina subclade showed more than $99.8 \%$ identity to B. bigemina reference sequences. Both $B$. bigemina and $B$. occultans were detected only in cattle (Fig. 2, Table 3, Additional file 1: Table S1).

A Hepatozoon canis sequence was detected in a lion and another Hepatozoon sp. was detected in a wild dog. Interestingly, a Colpodellidae sequence, ASV57, was also detected in cattle (Fig. 2, Additional file 1: Table S1).

\section{Discussion}

We applied the deep amplicon sequencing method to investigate piroplasmas $[17,21]$ in the wildlife and cattle population of the Kafue National Park and surrounding wildlife-livestock interface area of the greater Kafue ecosystem. Blood samples from 253 wild animals consisting 
Table 3 Diversity of piroplasmas detected in wildlife and cattle samples collected from the Kafue ecosystem

\begin{tabular}{|c|c|c|c|c|c|c|c|}
\hline Genus & Species & Genotypes & BLAST top hit & ID & OTU & ASV & $\%$ Identity \\
\hline \multirow[t]{36}{*}{ Theileria } & \multirow[t]{7}{*}{ T. velifera } & \multirow[t]{4}{*}{ T. velifera } & \multirow[t]{4}{*}{ T. velifera KSA_D_Th6 } & \multirow[t]{4}{*}{ LC431550 } & \multirow[t]{4}{*}{1} & 1 & 100.00 \\
\hline & & & & & & 7 & 99.78 \\
\hline & & & & & & 64 & 99.78 \\
\hline & & & & & & 92 & 99.78 \\
\hline & & T. velifera A & Theileria cf. velifera A & GU733375 & 2 & 6 & 98.69 \\
\hline & & \multirow[t]{2}{*}{ T. velifera B } & \multirow[t]{2}{*}{ Theileria cf. velifera (Syncerus caffer) clone $\mathrm{H} 4 \mathrm{a}$} & \multirow[t]{2}{*}{ JN572701 } & \multirow[t]{2}{*}{1} & 29 & 100.00 \\
\hline & & & & & & 55 & 99.78 \\
\hline & \multirow[t]{6}{*}{ T. mutans } & \multirow[t]{2}{*}{ T. mutans } & \multirow[t]{2}{*}{ Theileria mutans isolate MT15 } & \multirow[t]{2}{*}{ KU206320 } & \multirow[t]{2}{*}{11} & 3 & 100.00 \\
\hline & & & & & & 16 & 99.78 \\
\hline & & T. mutans MSD & Theileria sp. B15a & JN572700 & 12 & 5 & 100.00 \\
\hline & & T. mutans-like 1 & Theileria cf. mutans 1 (Syncerus caffer) clone C21b & JN572699 & 13 & 26 & 99.56 \\
\hline & & T. mutans-like 2 & Theileria cf. mutans 2 (Syncerus caffer) clone Q15d & JN572696 & 14 & 42 & 98.68 \\
\hline & & & & & & 60 & 98.46 \\
\hline & \multirow[t]{3}{*}{ T. parva } & & Theileria parva isolate F45P16 & MH929322 & 23 & 15 & 100.00 \\
\hline & & & Theileria parva & AF013418 & 23 & 86 & 99.78 \\
\hline & & & & & & 101 & 99.56 \\
\hline & \multirow[t]{4}{*}{ Theileria sp. (buffalo) } & & \multirow[t]{4}{*}{ Theileria sp. ex Syncerus caffer MCO-2011 clone V8b } & \multirow[t]{4}{*}{ HQ895982 } & \multirow[t]{4}{*}{23} & 10 & 100.00 \\
\hline & & & & & & 11 & 99.78 \\
\hline & & & & & & 18 & 99.56 \\
\hline & & & & & & 22 & 99.56 \\
\hline & Theileria sp. (bougasvlei) & & Theileria sp. KS-2015 isolate CAT79 & KP410267 & 22 & 25 & 100.00 \\
\hline & \multirow[t]{3}{*}{ T.taurotragi } & & \multirow[t]{3}{*}{ Theileria taurotragi } & L19082 & 20 & 35 & 97.80 \\
\hline & & & & & 21 & 46 & 99.78 \\
\hline & & & & & & 62 & 100.00 \\
\hline & Theileria sp. (sable) & & Theileria sp. BM-2010/sable & GU733378 & 16 & 8 & 99.78 \\
\hline & & & & & & 14 & 99.57 \\
\hline & & & & & & 85 & 99.35 \\
\hline & Theileria sp. (waterbuck) & & Theileria sp. NG-2013c isolate waterbuck 39 clone 6 & KF597072 & 19 & 4 & 99.35 \\
\hline & Theileria sp. (tsessebe) & & Theileria sp. ex Damaliscus lunatus clone TS22_11 & HQ179766 & 16 & 9 & 99.57 \\
\hline & & & & & & 23 & 99.78 \\
\hline & & & & & & 49 & 100.00 \\
\hline & Theileria sp. (giraffe) & & Theileria sp. NG-2012b isolate 44 clone 2 & JQ928925 & 15 & $2^{*}$ & 95.90 \\
\hline & & & & & & $106^{*}$ & 95.66 \\
\hline & & & & & & $47^{*}$ & 95.71 \\
\hline & Theileria sp. (bongo) & & Uncultured Theileria sp. isolate BNG13 & MH569462 & 17 & 12 & 97.82 \\
\hline & & & Uncultured Theileria sp. isolate BNG10 & MH569463 & 18 & 13 & 99.57 \\
\hline Babesia & B. bigemina & & Babesia bigemina clone PR28CL7 & MH050387 & 7 & 32 & 100.00 \\
\hline & & & & & & 71 & 99.77 \\
\hline & & & Babesia bigemina isolate B_bi11 & EF458200 & 7 & 67 & 100.00 \\
\hline & & & Babesia bigemina clone PR38CL1BBIG & MH047819 & 7 & 19 & 100.00 \\
\hline & Babesia sp. & & Babesia sp. 91093 cl1 & KX218437 & 10 & 58 & 98.95 \\
\hline & B. occultans & & Babesia occultans isolate Trender1 & KP745626 & 6 & 28 & 100.00 \\
\hline Hepatozoon & H. canis & & Hepatozoon canis isolate 70 & MK645969 & 8 & 40 & 99.60 \\
\hline & Hepatozoon sp. & & Hepatozoon sp. 2 BCS-2013 isolate L4 & KF270665 & 9 & 82 & 99.00 \\
\hline Colpodellidae & & & Uncultured Colpodellidae clone PL31 & MN103986 & 3 & 57 & 100.00 \\
\hline
\end{tabular}

ASV numbers shown in italics and with an asterisk represent the identity against the reference sequence of $100 \%$ and $95.7-95.9 \%$, respectively OTU operational taxonomic unit, $A S V$ amplicon sequence variant 


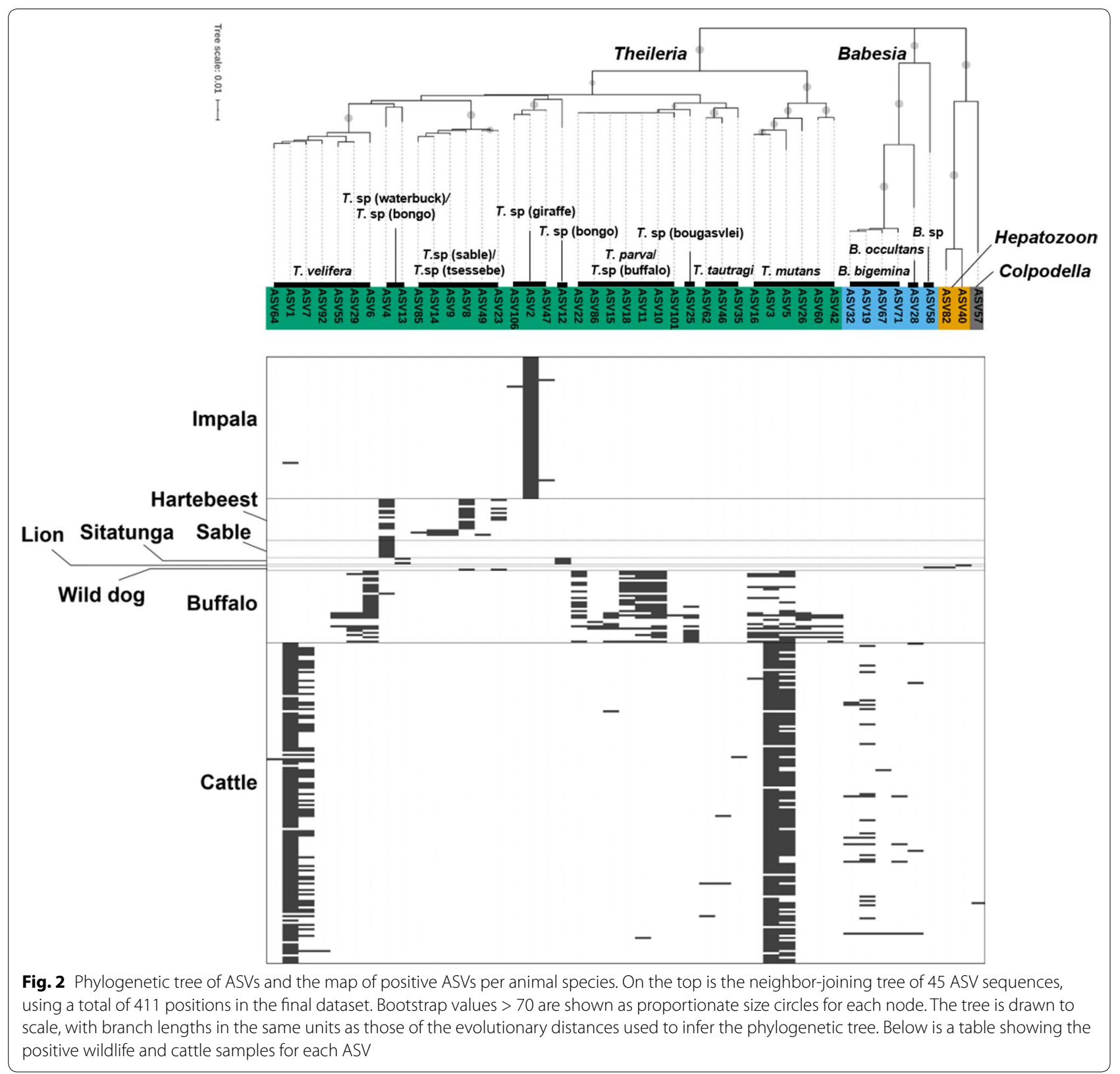

of 12 mammalian species and 232 cattle were collected in 2018 and 2019, respectively. Although the wildlife and cattle were sampled in different but consecutive years, this may not have affected the comparison and interpretation of the results obtained, because fundamental change of biodiversity in a functional and resilient ecosystem like Kafue takes a long period.

Our data show that 45 ASVs and 23 species consisting of 4 genera (Babesia, Theileria, Hepatozoon and Colpodella) were detected. Among the 45 ASVs, 14 were identical to previously published sequences. However, 28
ASVs demonstrated percentage identity of 95.7-99.8\%, suggesting that novel genotypes may also exist. ASV2, 47 and 106 presented $95.7-95.9 \%$ identity to Theileria sp., suggesting possible novel Theileria spp. or undeposited sequences of known Theileria spp. (asterisk in Table 3).

Within Theileria species, 36 ASVs were detected (Table 4). As an important natural reservoir host, buffalo had a diversity of 18 Theileria ASVs, which was the highest compared to other wildlife species. This finding is consistent with a previous report from a serological study involving buffalos [13]. Importantly, three ASVs of 
Table 4 Prevalence of species detected in the sampled wildlife species and cattle from the Kafue ecosystem

\begin{tabular}{|c|c|c|c|c|c|c|c|c|c|}
\hline Parasitic species & Impala & Hartebeest & Sable & Sitatunga & Lion & Wild dog & Buffalo & Cattle & Corresponding ASV \\
\hline T. velifera & $1(0.9 \%)$ & & & & & & $26(49.1 \%)$ & $136(58.6 \%)$ & $1,6,7,29,55,64,92$ \\
\hline T. mutans & & & & & & & $20(37.7 \%)$ & $140(60.3 \%)$ & $3,5,16,26,42,60$ \\
\hline T.parva & & & & & & & $8(15.1 \%)$ & $1(0.4 \%)$ & $15,86,101$ \\
\hline T. taurotragi & & & & & & & & $4(1.7 \%)$ & $35,46,62$ \\
\hline Theileria sp. (buffalo) & & & & & & & $26(49.1 \%)$ & $1(0.4 \%)$ & $10,11,18,22$ \\
\hline Theileria sp. (bougasvlei) & & & & & & & $10(18.9 \%)$ & & 25 \\
\hline Theileria sp. (sable) & & 15 (31.9\%) & & & & $1(50.0 \%)$ & & & $8,14,85$ \\
\hline Theileria sp. (waterbuck) & & $12(25.5 \%)$ & $8(100.0 \%)$ & & & & $1(1.9 \%)$ & & 4 \\
\hline Theileria sp. (tsessebe) & & $8(17.0 \%)$ & & & & $1(50.0 \%)$ & & & $9,23,49$ \\
\hline Theileria sp. (giraffe) & $65(61.3 \%)$ & & & & & & & & $2,47,106$ \\
\hline T.bongo & & & & $3(75.0 \%)$ & & & & & 12,13 \\
\hline B. bigemina & & & & & & & & $24(10.3 \%)$ & $19,32,67,71$ \\
\hline Babesia sp. & & & & & & $1(50.0 \%)$ & & & 58 \\
\hline B. occultans & & & & & & & & $4(1.7 \%)$ & 28 \\
\hline H. canis & & & & & $1(25.0 \%)$ & & & & 40 \\
\hline Hepatozoon sp. & & & & & & $1(50.0 \%)$ & & & 82 \\
\hline Colpodellodae & & & & & & & & $1(0.4 \%)$ & 57 \\
\hline Total head sampled & 106 & 47 & 8 & 4 & 4 & 2 & 53 & 232 & \\
\hline
\end{tabular}

ASVs amplicon sequence variants

T. parva (OTU23 comprising ASV15, 86 and 101) were obtained from buffalo, providing important epidemiological insight into cattle in the area in terms of corridor disease transmission. Indeed, T. parva ASV15 was detected in cattle $(\mathrm{Na} 032)$, suggesting possible spillover of T. parva from buffalo to domestic cattle. The presence of Theileria sp. (buffalo) (49.1\%; 26 of 53) and Theileria sp. (bougasvlei) (18.9\%; 10 of 53) in buffalo (Table 4) is of diagnostic importance as it affects the accurate detection of T. parva in mixed infections when performing hybridization PCR assay [33]. In addition to buffalo, Theileria sp. (buffalo) was also detected in the cattle population (0.4\%; 1 of 232). This result supports the observations and findings from studies conducted in Kenya that also identified Theileria sp. (buffalo) from cattle, suggesting that Theileria sp. (buffalo) infection in cattle occurs in the field where buffalo and cattle share pasture [20,34]. Nevertheless, more knowledge on the infection epidemiology and pathogenicity to cattle will be required. The presence of $T$. taurotragi circulating in the cattle population is consistent with findings in other similar studies [35]. The characterization of the parasite community and molecular ecology raises awareness about the consequences and limitations of specific diagnostic tests and requires further caution for the interpretation of the results used for diagnostics or surveillance in a specified area.

Babesia was predominantly observed in cattle but also detected in wild dogs. Babesia bigemina (10.3\%;
24 of 232 ) and B. occultans (1.7\%; 4 of 232) were the only species detected in cattle (Table 4 ), of which $B$. bigemina is a pathogenic parasite to cattle causing the clinical disorder of babesiosis, also known as redwater. These findings are similar to other comparable studies in southern Africa where the presence of Babesia in cattle and wild animals, particularly buffalo, was assessed [36]. To the best of our knowledge, this is the first report of the non-pathogenic B. ocultans in Zambia. However, its specific vectors, impact on cattle, diagnostic consequence in Babesia mixed infection and implication of infection to wildlife are not evaluated.

Despite not being classified in the order of piroplasmida but Eucoccidiorida, Apicomplexan species of Hepatozoon canis and Hepatozoon sp. were detected in African lion and wild dog samples, respectively. Divergent from other arthropod-borne parasites transmitted through the vector's salivary glands at the time of feeding, Hepatozoon are transmitted to the carnivore host exclusively by ingestion of infected vectors (ticks) during grooming $[37,38]$. They cause subclinical infection in wild carnivores and clinical infection in domestic dogs [39]. Previous studies on free-ranging wild carnivores in Zambia have indicated the widespread presence of Hepatozoon sp. in lions [40]. This highlights the considered epidemiological role of wild carnivores as a sylvatic reservoir of Hepatozoon and presents the risks 
of likely spillover of Hepatozoon infections to domestic carnivores in the interface area.

Genera of Colpodella are part of Alveolata organisms that are originally known to be free-living. However, recent studies have revealed the parasitic nature of Colpodella sp. as a human erythrocyte parasite (HEP) that has lately been reported from China to cause relapsing fevers and neurological symptoms in humans [41, 42]. Furthermore, the detection of Colpodella sp. in ticks suggests that this parasite may potentially be transmitted by tick vector(s) [41]. We detected a Colpodella sequence from one of the cattle samples, with the sequence identity of 79.6\% with the reported human cases (GQ411073; Colpodella sp. HEP). The sequence detected from our cattle sample showed a perfect match (100\% identity) to GenBank MN103986 (Colpodellidae clone PL31), reported in raccoon dog in Poland [43]. Thus, the detection of Colpodella sp. from a cattle sample implies support of those findings that some of the Colpodella species are associated with vertebrates and possibly cause disease. What vector is involved, how the parasite is maintained and the risk that the cattle may pose for human infection are largely undetermined. It would be important to determine the zoonotic scale of Colpodella infection to rule out incidental infections.

Identification of multiple infection is the another advantage of deep amplicon sequencing [21]. It is known that the African buffalo is simultaneously infected with multiple species of Theileria [44]. According to our study, the African buffalo is the most infected animal with multiple species of Theileria (see Fig. 2 and additional data; Additional file 1: Table S1). Besides, most of the cattle were also co-infected with Theileria velifera and Theileria mutans. It is reported that co-infection of multiple Theileria spp. in cattle results in dramatically different pathological disorders compared to singlespecies infections [45]. Further studies with expanded sample size might demonstrate similar interactions in wildlife as well. This is particularly important since Zambia's cattle population stronghold is in the Itezhi-Tezhi district which is adjacent to the KNP. This is cardinal as accurate diagnosis and effective control (vaccinations) of piroplasm parasites need to take the parasite community data into account. Hartebeest also tended to be coinfected with Theileria spp. In contrast, the impalas were mainly infected with Theileria spp. isolated from giraffe but hardly co-infected with other piroplasmas.

The identification of tick-borne pathogens in the wildlife and cattle population in the study area supports the apparent presence of the known tick vectors implicated in their transmission. Particular Theileria species are known to be transmitted by specific ixodid tick species of Rhipicephalus appendiculatus, R. zambeziensis and Amblyomma variegatum, while Babesia species are transmitted by $R$. microplus, $R$. decororatus and $R$. everts $i$ $[46,47]$. The tick species associated with transmission of Hepatozoon species is the Rhipicephalus sanguineus sensu lato (s.l.) [48]. To identify the unknown vectors of some of the parasites described in this study, there is need to conduct tick piroplasm metagenomic analysis. This would further illustrate the piroplasm parasite ecocycle more precisely.

\section{Conclusion}

Molecular epidemiology based on the strength of knowledge of the cryptic parasite community and diversity is essential in the control of piroplasmosis. Mapping of the piroplasm parasites in all major livestock landscapes beyond the Kafue ecosystem using the metagenomic approach may benefit piroplasmosis control in Zambia through high-resolution data to precisely guide diagnosis, vaccination and movement controls.

\section{Supplementary information}

Supplementary information accompanies this paper at https://doi. org/10.1186/s13071-020-04475-7.

Additional file 1. Metadata from Illumina MiSeq sequencing and ASV analysis.

\section{Acknowledgements}

We thank the Department of National Parks and Wildlife (DNPW) and the Itezhi-Tezhi farmers in Zambia for the permission to conduct this research in the greater Kafue ecosystem. The authors also acknowledge the Wildlife Veterinary Unit (WVU) for their role and assistance in the wildlife sample collection.

\section{Authors' contributions}

DS, YN collected samples and wrote the manuscript. DS, YN, NK, KH and JY conducted laboratory experiments and analyzed the data. $\mathrm{HC}$ collected samples. JY, KH, BN and CS designed the study, supervised the work and critically revised the manuscript. All authors read and approved the final manuscript.

\section{Funding}

This study was funded by the Japan Society for the Promotion of Science Ronpaku Program (JSPS) Japan and "Japan Program for Infectious Diseases Research and Infrastructure" from Japan Agency for Medical Research and Development (AMED) under grant number JP20w m0125008.

\section{Availability of data and materials}

Data supporting the conclusions of this article are included within the article and its additional file. Representative ASV sequences were deposited in the GenBank database under the accession numbers MT814722-MT814766.

\section{Ethics approval and consent to participate}

The permission to collect blood samples from the free-ranging wildlife of the greater Kafue ecosystem and authority to use the samples for this study were granted by the Department of National Parks and Wildlife (DNPW) in Zambia (TJNPW/8/27/1). The blood samples from cattle were collected under the permission from ethics approval ref. no. 2019-Feb-081 (ERES Converge IRB, Lusaka, Zambia). 


\section{Consent of publication}

Not applicable.

\section{Competing interests}

The authors declare that they have no competing interests.

\begin{abstract}
Author details
${ }^{1}$ Research Center for Zoonosis Control, Hokkaido University, Sapporo, Japan. ${ }^{2}$ Wild life Veterinary Unit, Department of National Parks and Wildlife, Chilanga, Zambia. ${ }^{3}$ The Royal (Dick) School of Veterinary Studies, University of Edinburgh, Edinburgh, UK. ${ }^{4}$ Central Veterinary Research Institute, Ministry of Fisheries and Livestock, Chilanga, Zambia. ${ }^{5}$ Department of Paraclinical Studies, University of Zambia, Lusaka, Zambia. ${ }^{6}$ International Collaboration Unit, Research Center for Zoonosis Control, Hokkaido University, Sapporo, Japan.
\end{abstract}

Received: 4 August 2020 Accepted: 5 November 2020 Published online: 30 November 2020

\section{References}

1. Schreeg ME, Marr HS, Tarigo JL, Cohn LA, Bird DM, Scholl EH, et al. Mitochondrial genome sequences and structures aid in the resolution of piroplasmida phylogeny. PLoS ONE. 2016;11:e0165702.

2. Allsopp MTEP, Cavalier-Smith T, Waal DTDE, Allsopp BA. Phylogeny and evolution of the piroplasms. Parasitology. 1994;108:147-52.

3. Bishop R, Musoke A, Morzaria S, Gardner M, Nene V. Theileria: intracellular protozoan parasites of wild and domestic ruminants transmitted by ixodid ticks. Parasitology. 2004;129:S271-83.

4. Criado-fornelio A, Martinez-marcos A, Buling-Saraña A, Barba-Carretero JC. Molecular studies on Babesia, Theileria and Hepatozoon in southern Europe Part II. Phylogenetic analysis and evolutionary history. Vet Parasitol. 2003;114:173-94.

5. Criado-Fornelio A, Gónzalez-Del-Río MA, Buling-Saraña A, Barba-Carretero JC. The 'expanding universe' of piroplasms. Vet Parasitol. 2004;119:337-45.

6. Kock R, Kock M, De Garine-wichatitsky M, Chardonnet P, Caron A. Livestock and buffalo (Syncerus caffer) interfaces in Africa: ecology of disease transmission and implications for conservation and development. In: Melletti M, Burton J, editors. Ecology, evolution and behaviour of wild cattle implications for conservation. University of Cambridge: Cambridge; 2014. p. 431-45.

7. Morrison WI, Hemmink JD, Toye PG. Theileria parva: a parasite of African buffalo, which has adapted to infect and undergo transmission in cattle. Int J Parasitol. 2020;50:403-12.

8. Yusufmia SBAS, Collins NE, Nkuna R, Troskie M, Van Den Bossche P, Penzhorn BL. Occurrence of Theileria parva and other haemoprotozoa in cattle at the edge of Hluhluwe-iMfolozi Park, KwaZulu-Natal, South Africa. J S Afr Vet Assoc. 2010;81:45-9.

9. Uilenberg G. Immunization against diseases caused by Theileria parva: a review. Trop Med Int Health. 1999;4:A12-20.

10. Nene V, Musoke A, Gobright E, Morzaria S. Conservation of the sporozoite p67 vaccine antigen in cattle-derived Theileria parva stocks with different cross-immunity profiles. Infect Immun. 1996;64:2056-61.

11. Bandyopadhyay S, Tembo G. Household consumption and natural resource management around national parks in Zambia. J Nat Resour Policy Res. 2010;2:39-55.

12. Kock RA. What is this infamous "wild life/livestock disease interface?" a review of current knowledge for the African continent. In: Osofsky SA, editor. Conservation and development interventions at the wildlife/ livestock interface: implications for wildlife, livestock and human health. Switzerland and Cambridge: IUCN, Gland; 2005. p. 1-13.

13. Munang'andu HM, Siamudaala V, Matandiko W, Mulumba M, Nambota A, Munyeme $M$, et al. Detection of Theileria parva antibodies in the African buffalo (Syncerus caffer) in the livestock-wildlife interface areas of Zambia. Vet Parasitol. 2009;166:163-6.

14. Hemmink JD, Sitt T, Pelle R, De K-L, Shiels B, Toye PG, et al. Ancient diversity and geographical sub-structuring in African buffalo Theileria parva populations revealed through metagenetic analysis of antigen-encoding loci. Int J Parasitol. 2018;48:287-96.
15. Pienaar R, Latif AA, Thekisoe OMM, Mans BJ. Geographic distribution of Theileria sp. (buffalo) and Theileria sp. (bougasvlei) in Cape buffalo (Syncerus caffer) in southern Africa: implications for speciation. Parasitology. 2014;141:411-24.

16. Eygelaar D, Jori F, Mokopasetso M, Sibeko KP, Collins NE, Vorster I, et al. Tick-borne haemoparasites in African buffalo (Syncerus caffer) from two wildlife areas in northern Botswana. Parasites Vectors. 2015;8:1-11.

17. Glidden CK, Koehler AV, Hall RS, Saeed MA, Coppo M, Beechler BR, et al. Elucidating cryptic dynamics of Theileria communities in African buffalo using a high-throughput sequencing informatics approach. Ecol Evol. 2019;10:70-80

18. Muleya W, Namangala B, Simuunza M, Nakao R, Inoue N, Kimura T, et al. Population genetic analysis and sub-structuring of Theileria parva in the northern and eastern parts of Zambia. Parasites Vectors. 2012;5:255.

19. Geysen D, Bishop R, Skilton R, Dolan TT, Morzaria S. Molecular epidemiology of Theileria parva in the field. Trop Med Int Health. 1999;4:A21-7.

20. Bishop RP, Hemmink JD, Morrison WI, Weir W, Toye PG, Sitt T, et al. The African buffalo parasite Theileria sp. (buffalo) can infect and immortalize cattle leukocytes and encodes divergent orthologues of Theileria parva antigen genes. Int J Parasitol Parasites Wildl. 2015;4:333-42.

21. Chaudhry U, Ali Q, Rashid I, Shabbir MZ, ljaz M, Abbas M, et al. Development of a deep amplicon sequencing method to determine the species composition of piroplasm haemoprotozoa. Ticks Tick Borne Dis. 2019;10:101276.

22. Kock MD, Burroughs REJ. Chemical and physical restraint of wild animals: a training and field manual for African species. Greyton: IWVS; 2012.

23. La Grange M. The capture, care, and management of wildlife. Pretoria: Van Schaik; 2006.

24. Gubbels JM, De Vos AP, Van Der Weide M, Viseras J, Schouls LM, De Vries E, et al. Simultaneous detection of bovine Theileria and Babesia species by reverse line blot hybridization. J Clin Microbiol. 1999;37:1782-9.

25. Bolger AM, Lohse M, Usadel B. Trimmomatic: a flexible trimmer for illumina sequence data. Bioinformatics. 2014;30:2114-20.

26. Palmer JM, Jusino MA, Banik MT, Lindner DL. Non-biological synthetic spike-in controls and the AMPtk software pipeline improve mycobiome data. PeerJ. 2018;6:e4925.

27. Altschul SF, Gish W, Miller W, Myers EW, Lipman DJ. Basic local alignment search tool. J Mol Biol. 1990:215:403-10.

28. Edgar RC. Search and clustering orders of magnitude faster than BLAST. Bioinformatics. 2010:26:2460-1.

29. Saitou N, Nei M. The neighbor-joining method: a new method for reconstructing phylogenetic trees. Mol Biol Evol. 1987:4:406-25.

30. Kumar S, Stecher G, Li M, Knyaz C, Tamura K. MEGA X: molecular evolutionary genetics analysis across computing platforms. Mol Biol Evol. 2018;35:1547-9.

31. Tamura K, Tao Q, Kumar S. Theoretical foundation of the reltime method for estimating divergence times from variable evolutionary rates. Mol Biol Evol. 2018;35:1770-82.

32. Letunic I, Bork P. Interactive tree of life (iTOL) v4: recent updates and new developments. Nucleic Acids Res. 2019;47:W256-9.

33. Pienaar R, Potgieter FT, Latif AA, Thekisoe OMM, Mans BENJ. Mixed Theileria infections in free-ranging buffalo herds: implications for diagnosing Theileria parva infections in Cape buffalo (Syncerus caffer). Parasitology. 2011;138:884-95.

34. Githaka N, Konnai S, Bishop R, Odongo D, Lekolool I, Kariuki E, et al. Identification and sequence characterization of novel Theileria genotypes from the waterbuck (Kobus defassa) in a Theileria parva-endemic area in Kenya. Vet Parasitol. 2014;202:180-93.

35. Mans BJ, Pienaar R, Latif AA, Potgieter FT. Diversity in the 18S SSU rRNA $\checkmark 4$ hyper-variable region of Theileria spp. in Cape buffalo (Syncerus caffer) and cattle from southern Africa. Parasitology. 2011;138:766-79.

36. Mans BJ, Pienaar R, Ratabane J, Pule B, Latif AA. Investigating the diversity of the 18S SSU rRNA hyper-variable region of Theileria in cattle and Cape buffalo (Syncerus caffer) from southern Africa using a next generation sequencing approach. Ticks Tick Borne Dis. 2016;7:869-79.

37. Smith TG. The genus Hepatozoon (Apicomplexa: Adeleina). J Parasitol. 1996;82:565-85.

38. Greene CE. Infectious diseases of the dog and cat. 4th ed. Missouri: Elsevier Saunders; 2012. p. 750-7. 
39. Cunningham MW, Yabsley MJ. Primer on tick-borne diseases in exotic carnivores. In: Fowler's zoo and wild animal medicine current therapy, vol. 7. St. Louis: Elsevier Inc.; 2012. p. 458-64.

40. Williams BM, Berentsen A, Shock BC, Teixiera M, Dunbar MR, Matthew BS, et al. Prevalence and diversity of Babesia, Hepatozoon, Ehrlichia, and Bartonella in wild and domestic carnivores from Zambia, Africa. Parasitol Res. 2014;113:911-8.

41. Jiang J, Jiang R, Chang Q, Zheng Y, Von FE, Cao W. Potential novel tickborne Colpodella species parasite infection in patient with neurological symptoms: case report. PLoS Negl Trop Dis. 2018;12:e0006546.

42. Yuan CL, Keeling PJ, Krause PJ, Horak A, Bent S, Rollend L, et al. Colpodella spp._-like parasite infection in woman, China. Emerg Infect Dis. 2012;18:125-7.

43. Solarz W, Najberek K, Wilk-Woźniak E, Biedrzycka A. Raccoons foster the spread of freshwater and terrestrial microorganisms-mammals as a source of microbial eDNA. Divers Distrib. 2020;26:453-9.

44. Mans BJ, Pienaar R, Latif AA. A review of Theileria diagnostics and epidemiology. Int J Parasitol Parasites Wildl. 2015:4:104-18.
45. Woolhouse MEJ, Thumbi SM, Jennings A, Chase-Topping M, Callaby R, Kiara $\mathrm{H}$, et al. Co-infections determine patterns of mortality in a population exposed to parasite infection. Sci Adv. 2015;1:e1400026.

46. Makala LH, Mangani P, Fujisaki K, Nagasawa H. The current status of major tick borne diseases in Zambia. Vet Res. 2003;34:27-45.

47. Simuunza M, Weir W, Courcier E, Tait A, Shiels B. Epidemiological analysis of tick-borne diseases in Zambia. Vet Parasitol. 2011;175:331-42.

48. Qiu Y, Kaneko C, Kajihara M, Ngonda S, Simulundu E, Muleya W, et al. Tick-borne haemoparasites and Anaplasmataceae in domestic dogs in Zambia. Ticks Tick Borne Dis. 2018;9:988-95.

\section{Publisher's Note}

Springer Nature remains neutral with regard to jurisdictional claims in published maps and institutional affiliations.
Ready to submit your research? Choose BMC and benefit from:

- fast, convenient online submission

- thorough peer review by experienced researchers in your field

- rapid publication on acceptance

- support for research data, including large and complex data types

- gold Open Access which fosters wider collaboration and increased citations

- maximum visibility for your research: over $100 \mathrm{M}$ website views per year

At BMC, research is always in progress.

Learn more biomedcentral.com/submissions 